\title{
Efecto de la fertilización con distintas concentraciones de nitrógeno y potasio en el crecimiento de plantines de ciprés de la cordillera (Austrocedrus chilensis) en vivero
}

\author{
Fertilization effect of different concentrations of nitrogen and potassium \\ in the growth of Austrocedrus chilensis seedlings in nursery
}

\author{
Diego S Massone ${ }^{\mathrm{a}, \mathrm{b} *}$, Carlos G Bartoli ${ }^{\mathrm{c}}$, Mario J Pastorino ${ }^{\mathrm{d}}$ \\ *Autor de correspondencia: ${ }^{\text {a }}$ Universidad Nacional de la Patagonia San Juan Bosco, Unidad de Propagación Vegetal - INBIES, \\ Esquel, Argentina, diego-massone@hotmail.com.ar \\ ${ }^{\mathrm{b}}$ Universidad Nacional de la Patagonia San Juan Bosco, Facultad de Ingeniería Forestal, Esquel, Argentina. \\ ${ }^{\mathrm{c}}$ Universidad Nacional de La Plata, Facultad de Ciencias Agrarias y Forestales, Instituto de Fisiología Vegetal, La Plata, Argentina. \\ ${ }^{\mathrm{d}}$ INTA EEA Bariloche, Unidad de Genética Ecológica y Mejoramiento Forestal, Bariloche, Argentina.
}

\begin{abstract}
SUMMARY
Nitrogen $(\mathrm{N})$ is an element with a high influence in seedling growth in the nursery. Nevertheless, absolute levels of nutrient concentration are irrelevant if the relationship among the major elements is not examined. In this work we studied the incidence of several $\mathrm{N}$ concentrations in two proportional relationships with potassium $(\mathrm{K})$, keeping the relationship with phosphate (P) constant (i.e. 3:2:1 and 3:2:3 for N:P:K), during the rapid growing phase in the fertigation production of Austrocedrus chilensis seedlings. Seedling height, stem diameter at the collar level, total biomass, aboveground/underground biomass ratio (PSA/PSR), nutritional status and root growth potential (RGP) were measured at the end of the growing season. The two treatments combining lower concentration of $\mathrm{N}$ with a relationship 3:2:3 produced the highest effect on all morphological parameters assessed. The PSA/PSR was more equilibrated in the treatments with the relationship 3:2:3. The $\mathrm{N}$ concentration in the leaves was proportional to its concentration in the nutrient solution. The P content did not show differences among treatments, whereas the $\mathrm{K}$ level was higher for the treatment of lower $\mathrm{N}$ concentration with relationship 3:2:1. The RGP was low in all treatments. Our observations showed that the 3:2:3 relationship produced larger seedlings with a better balance of biomass partition, evidencing that the management of $\mathrm{K}$ in the nutrient solution has higher influence in the seedlings growth of Austrocedrus chilensis.
\end{abstract}

Key words: nutrition, morphological growth parameters, greenhouse, RGP.

\section{RESUMEN}

El nitrógeno es uno de los nutrientes más influyentes sobre el crecimiento de los plantines en un vivero. Sin embargo, la concentración de cada nutriente carece de importancia si no se la analiza en relación al conjunto de ellos. En este trabajo sobre la producción bajo fertirriego de plantines de ciprés de la cordillera, se estudió la incidencia de distintos niveles de concentración de nitrógeno (50,100, 150 y $\left.200 \mathrm{mg} \mathrm{L}^{-1}\right)$ en dos relaciones proporcionales con el potasio, manteniendo invariable la relación con el fósforo (i.e. 3:2:1 y 3:2:3 para $\mathrm{N}: \mathrm{P}: \mathrm{K}$ ), durante la etapa de crecimiento rápido. Se evaluaron la altura, el diámetro al cuello del plantín, la biomasa total, la asignación entre la parte aérea y radical (PSA/PSR), el estado nutricional y el potencial de crecimiento radical (PCR). Los tratamientos con menor concentración de nitrógeno y de proporciones 3:2:3 produjeron el mayor incremento en los parámetros morfológicos analizados. La PSA/PSR fue más equilibrada en los tratamientos con relación 3:2:3. La concentración foliar de nitrógeno fue proporcional a su concentración en la solución nutritiva. La concentración foliar de fósforo no mostró diferencias, mientras que se observó una mayor concentración foliar de potasio en el tratamiento de menor concentración de nitrógeno y relación 3:2:1. El PCR mostró valores bajos en todos los tratamientos. Las observaciones indican que la relación 3:2:3 produjo plantines de mayor tamaño y con asignaciones de biomasa más balanceadas, evidenciando que el manejo del potasio tuvo gran influencia en el crecimiento del ciprés de la cordillera en vivero.

Palabras clave: nutrición, parámetros de crecimiento, invernadero, PCR.

\section{INTRODUCCIÓN}

Los bosques de ciprés de la cordillera (Austrocedrus chilensis (D. Don) Pic. Ser. et Bizzarri) se distribuyen en
Argentina desde los $37^{\circ} 7^{\prime} \mathrm{S}$ hasta los $43^{\circ} 44^{\prime} \mathrm{S}$ (Pastorino et al. 2006) en una franja de $750 \mathrm{~km}$ siguiendo las laderas de la Cordillera de Los Andes en sentido norte-sur y de unos 10 a $50 \mathrm{~km}$ en el sentido este-oeste, ubicándose en 
las provincias de Neuquén, Río Negro y Chubut (Donoso 1993).

Los incendios de gran magnitud son eventos cada vez más frecuentes en los bosques andino-patagónicos. En el período comprendido entre 1993 y 1999, aproximadamente 57.930 hectáreas de bosque nativo fueron afectadas por incendios forestales en las provincias de Río Negro y Chubut. En el año 2015 se quemaron 44.257 ha de bosque nativo en las provincias de Neuquén, Río Negro y Chubut, correspondiendo 27.101 ha a un solo incendio (Las Horquetas - Cholila) (Mohr Bell 2015). La regeneración natural de A. chilensis ocurre en el largo plazo, ya que requiere que la especie recolonice el sitio a través de semilla desde los remanentes del incendio. Esto hace que en muchos casos los cipresales quemados transiten una conversión antrópica hacia forestaciones con especies de rápido crecimiento y silvicultura probada, o más frecuentemente, hacia potreros ganaderos (Urretavizcaya 2001).

Uno de los requisitos para llevar a cabo una restauración activa de los cipresales quemados es contar con un sistema eficiente de producción masiva de plantines de $A$. chilensis. A la fecha existen escasos trabajos publicados sobre producción de plantines en viveros de la región andino-patagónica de la Argentina, tanto para coníferas exóticas (e.g. Basil et al. 2002, Lavado y Mazzarino 2005), como para especies nativas (Azpilicueta et al. 2010, Schinelli 2013) y A. chilensis en particular (Enricci y Massone 2003). Si bien aún se continúan utilizando métodos tradicionales de bajo aporte tecnológico, existen tecnologías modernas para la producción de plantines forestales que se basan en el cultivo sobre sustrato inerte en contenedores con fertirriego dentro de invernáculos.

Para asegurar el éxito de los planes de restauración a partir del establecimiento de plantines de $A$. chilensis cultivados bajo cobertura, es necesario conformar protocolos que mejoren este tipo de viverización, buscando lotes uniformes y de calidad conocida, lo que además permitirá caracterizar los plantines de manera de evaluar más ajustadamente su comportamiento a campo. El ajuste de los distintos factores intervinientes en el cultivo es de vital importancia para lograr plantines aptos para las condiciones edafo-climáticas del sitio a restaurar, tomando este aspecto mayor relevancia ante un escenario de cambio climático. Debido al pronunciado efecto de la fertilización sobre el crecimiento de las plantas, los niveles de los nutrientes son ajustados para las distintas etapas fenológicas del cultivo. Se diferencian tres etapas principales: el establecimiento, que abarca desde la germinación hasta el fin de la etapa cotiledonar; el pleno crecimiento, cuando tiene lugar el crecimiento en altura a una tasa exponencial, y la fase de rustificación, en la que el plantín cesa su crecimiento en altura, forma yemas e incrementa el diámetro del tallo y el volumen de raíces. Todas estas etapas de crecimiento son muy lentas en plantas de A. chilensis comparadas con las de otras especies forestales cultivadas comúnmente en la región. Landis et al. (1989) mencionan a la fertilización como una de las prácticas culturales más influyentes tanto en la tasa como en el tipo de crecimiento de plantines producidos bajo este método. Sin embargo, existe escasa información sobre la respuesta de las plantas de A. chilensis a la disponibilidad de minerales. La generación de este conocimiento permitirá optimizar el manejo de los esquemas de fertilización, mejorando los tiempos de viverización y contribuyendo al desarrollo de plantines de $A$. chilensis con las características morfo-fisiológicas ajustadas al sitio a restaurar.

El nitrógeno es uno de los elementos nutrientes que más influyen sobre el crecimiento. Por otro lado, los valores absolutos de los niveles de cada nutriente determinados en el follaje carecen de importancia si no se analiza la relación proporcional entre los principales elementos. $\mathrm{Al}$ respecto, una planta puede estar muy bien provista en los contenidos de nitrógeno pero si el contenido de potasio es bajo, la relación entre ambos elementos no permitirá que la planta exprese todo su potencial en aspectos tales como resistencia al frío, capacidad para producir nuevas raíces y crecimiento inicial (Escobar 2007). El potasio ha sido sugerido como un importante regulador catiónico de las células vegetales para el mantenimiento del $\mathrm{pH}$ del citoplasma y el estroma de cloroplastos (Wu y Berkowitz 1992). La deficiencia en potasio provoca una disminución del $\mathrm{pH}$ del estroma, resultando en una caída de la actividad fotosintética (Werdan et al. 1975). Watanabe et al. (2011) sugieren que la deficiencia de otros nutrientes tales como el fósforo y potasio, en relación al uso eficiente del nitrógeno, limitaría la actividad fotosintética bajo elevadas concentraciones de $\mathrm{CO}_{2}$ atmosférico.

En este trabajo se contrasta la hipótesis de que el crecimiento del $A$. chilensis en vivero está determinado por los niveles foliares de nitrógeno y por la relación proporcional de este con el potasio que actúa como factor limitante. Para ello se estudió la incidencia de distintos niveles de concentración de nitrógeno en combinación con dos relaciones de proporción con el potasio durante la etapa de pleno crecimiento en plantines del año sometios a un sistema de producción por fertirriego. Los objetivos específicos consisten en (i) evaluar el efecto sobre el crecimiento de la porción aérea, la asignación de biomasa, el potencial de crecimiento radical (PCR) y la tasa de acumulación en hojas de nitrógeno, fósforo, potasio, calcio y magnesio; y (ii) definir las relaciones nutricionales que generan los mayores crecimientos, las relaciones de biomasa más balanceadas y los mayores valores de PCR.

\section{MÉTODOS}

Material vegetal y ambiente de cultivo. Los experimentos se llevaron a cabo con plantas de $A$. chilensis generadas a partir de semillas cosechadas en el año 2012 en un rodal natural de la especie de las cercanías de la localidad de Corcovado, Provincia de Chubut ( $43^{\circ} 32^{\prime} 36,5^{\prime}$ ' S - 71 ${ }^{\circ} 29^{\prime}$ 14,6” W), el cual corresponde a la Región de Procedencia 
Sur (Pastorino et al. 2015). La cosecha se efectuó directamente de las copas, muestreando 16 árboles de polinización abierta separados por al menos $30 \mathrm{~m}$ de distancia, de tal modo de minimizar la probabilidad de muestrear árboles emparentados y asegurar una base genética amplia. Dado que la diferenciación genética entre poblaciones de la especie es baja, y que la mayor diversidad genética se halla al interior de las poblaciones naturales (Pastorino et al. 2004), este muestreo aseguró una aceptable representación del acervo genético de la especie. El pre-tratamiento de siembra consistió en imbibición en agua durante $48 \mathrm{~h}$, seguido de oreado de las semillas y estratificación con arena frío-húmeda a $3{ }^{\circ} \mathrm{C} / 5{ }^{\circ} \mathrm{C}$ durante 45 días. Se les incorporó un fungicida en polvo (CAPTAN ${ }^{\circledR}$ ) antes de comenzar la estratificación, para prevenir la contaminación con hongos. Se sembró directamente en la bandeja de cultivo a una densidad de seis semillas por cavidad. En las cavidades que emergieron más de una plántula, luego del desarrollo completo de los cotiledones se realizó un raleo, dejando una sola por celda. Los plantines se cultivaron en un invernadero perteneciente al vivero del Instituto de Biotecnología de Esquel (INBIES) de la Universidad Nacional de la Patagonia SJB ( $42^{\circ} 55^{\prime} 55,51^{\prime \prime} \mathrm{S}, 71^{\circ} 21^{\prime}$ 50,17 ” W, 560 m s.n.m.). Durante la fase de establecimiento y pleno crecimiento se colocó en la parte superior del invernadero una malla media sombra aluminizada al $50 \%$. En estas etapas de crecimiento las temperaturas mínimas se mantuvieron por encima de $\operatorname{los} 15^{\circ} \mathrm{C}$ y las máximas por debajo de los $30^{\circ} \mathrm{C}$. Como sustrato se usó una mezcla de turba Sphagnum sp. (procedente de turberas de Tierra del Fuego) y perlita, en una proporción 2:1. Se eligieron bandejas de cultivo con 30 cavidades troncocónicas de $160 \mathrm{~cm}^{3}$, de sección circular, con orificios de autopoda radicular y nervaduras anti-enrulado (DASSPLASTIC $\AA$, modelo 30160).

Manejo de agua y fertirriego. Luego de la siembra se realizaron riegos frecuentes para mantener el contenido de humedad del sustrato lo más cercano posible a capacidad de contenedor $(\mathrm{Cc})$ en los primeros centímetros del mismo. Este estado hídrico del medio de crecimiento es el que resulta luego de un riego a percolación y una vez que la misma cesa. Al producirse la germinación, la frecuencia de riego se estableció usando el método de las pesadas, descripto por Landis et al. (1989), a partir del establecimiento de diferentes estados hídricos del medio de crecimiento, definidos en función de porcentajes del agua aprovechable del sistema suelo-planta. La misma se definió como:

$$
\mathrm{AA}=\mathrm{Cc}-\mathrm{PMI}
$$

Siendo AA: agua aprovechable y PMI: punto de marchitez incipiente, que es el estado hídrico del medio de crecimiento una vez que el plantín llega al punto de pérdida de turgor celular.
Para inferir el peso del punto de marchitez incipiente (PMI), se construyó una curva de presión-volumen (P-V) utilizando el método de transpiración libre mencionado por Fernández y Gyenge (2010). A través de la curva se definió el contenido relativo de agua (CRA) al cual los plantines de ciprés llegaban a un estado hídrico celular de pérdida de turgencia (TLP), siendo el mismo de 0,82.

Así definida AA, en la fase de establecimiento se efectuó el riego al $75 \%$, en pleno crecimiento al $50 \%$ y en rustificación al $40 \%$ de AA.

El riego se aplicó en forma manual mediante la utilización de un conjunto formado por una bomba periférica y un aplicador en forma de roseta. Tanto en la fase de establecimiento como en la de rustificación se utilizaron soluciones fertilizantes únicas para todos los tratamientos. En la fase de establecimiento se usó una solución nutritiva con una concentración de nitrógeno $=64 \mathrm{mg} \mathrm{L}^{-1}$, fósforo $=152 \mathrm{mg} \mathrm{L}^{-1}$ y potasio $=61 \mathrm{mg} \mathrm{L}^{-1}$. Para llegar a estos valores se diluyó por litro de agua $0,15 \mathrm{~g}$ del fertilizante COMPO ${ }^{\circledR} \mathrm{HAKAPHOS}$ violeta (13-40-13); $0,4 \mathrm{~g}$ de fosfato monoamónico; $0,125 \mathrm{~g}$ de fosfato monopotásico y $0,02 \mathrm{~mL}$ de ácido fosfórico al $85 \%$. Para la solución de aplicación utilizada en la fase de rustificación se diluyó en un litro de agua $0,34 \mathrm{~g}$ de fertilizante $\mathrm{COMPO}^{\circledR}$ HAKAPHOS base (7-12-40); 0,23 g de fosfato monoamónico; $0,1 \mathrm{~g}$ de fosfato monopotásico y $0,02 \mathrm{ml}$ de ácido fosfórico al $85 \%$ alcanzándose una concentración de nitrógeno $=49 \mathrm{mg} \mathrm{L}^{-1}$, de fósforo $=100 \mathrm{mg} \mathrm{L}^{-1} \mathrm{y}$ de potasio $=150 \mathrm{mg} \mathrm{L}^{-1}$. En la fase de crecimiento rápido se usaron diferentes soluciones fertilizantes según los tratamientos aplicados.

Tratamientos. Consistieron en la variación de las soluciones nutritivas durante la fase de crecimiento rápido. Se estableció un ensayo con ocho soluciones nutritivas; cuatro de ellas tuvieron una relación N:P:K de 3:2:1, diferenciándose por sus dosis crecientes de nitrógeno, siendo estas $50,100,150$ y $200 \mathrm{mg} \mathrm{L}^{-1}$. En las otras cuatro soluciones, se mantuvieron las mismas dosis crecientes de nitrógeno y se igualó la concentración de potasio a la de nitrógeno, llegándose a una relación N:P:K de 3:2:3. Los distintos tratamientos se generaron a través de la dilución de diferentes sales hidrosolubles en agua (cuadro1). El agua de riego usada en los ensayos, contenía $10 \mathrm{mg} \mathrm{L}^{-1}$ de potasio, $4 \mathrm{mg} \mathrm{L}^{-1}$ de magnesio, $19 \mathrm{mg} \mathrm{L}^{-1}$ de sulfatos y $67 \mathrm{mg} \mathrm{L}^{-1}$ de calcio. El aporte de estos iones fue tomado en cuenta al momento de diseñar las distintas soluciones nutritivas.

Variables analizadas. Se midieron variables de crecimiento en la parte aérea, potencial de crecimiento radical y contenido de nutrientes en la porción aérea, sobre plantines con el primer ciclo vegetativo completo (i.e. una vez concluida la fase de rustificación, durante el mes de mayo).

La altura final del plantín se determinó como la distancia desde la base del tallo (cuello) hasta el ápice del eje primario de la planta. El diámetro final del cuello se estableció como el diámetro del tallo medido a la altura de la 
Cuadro 1. Clases y concentraciones de las sales fertilizantes de los ocho tratamientos utilizados en el ensayo.

Classes and concentrations of the fertilizer salts of the 8 treatments tested.

Tratamiento

Soluciones nutritivas expresadas en gramos de sales fertilizantes hidrosolubles por litro de agua

T1 $(3: 2: 1-\mathrm{N}: 50)$

0,046 COMPO ${ }^{\circ}$ HAKAPHOS rojo (18-18-18); *0,02 $\mathrm{H}_{3} \mathrm{PO}_{4}$ al $85 \% ; 0,086 \mathrm{NH}_{4} \mathrm{H}_{2} \mathrm{PO}_{4}$ y $0,29\left(\mathrm{NO}_{3}\right){ }_{2} \mathrm{Mg}$.

T2 (3:2:1 - N:100) 0,15 COMPO® HAKAPHOS rojo (18-18-18); *0,01 $\mathrm{H}_{3} \mathrm{PO}_{4}$ al 85 \%; 0,155 NH $\mathrm{NH}_{2} \mathrm{PO}_{4} ; 0,18\left(\mathrm{NO}_{3}\right) \mathrm{Mg}_{2}$ y 0,08 Urea.

T3 (3:2:1 - N:150) 0,26 COMPO® HAKAPHOS rojo (18-18-18); *0,01 $\mathrm{H}_{3} \mathrm{PO}_{4}$ al $85 \%$; 0,35 NH $\mathrm{H}_{2} \mathrm{PO}_{4} ; 0,18\left(\mathrm{NO}_{3}\right) \mathrm{Mg}_{2}$ y, 1 Urea.

T4 (3:2:1 - N200) 0,38 COMPO ${ }^{\circ}$ HAKAPHOS rojo (18-18-18); *0,01 $\mathrm{H}_{3} \mathrm{PO}_{4}$ al 85 \%; 0,46 $\mathrm{NH}_{4} \mathrm{H}_{2} \mathrm{PO}_{4} ; 0,33\left(\mathrm{NO}_{3}\right) \mathrm{Mg}_{2}$ y $0,1 \mathrm{Urea}$.

T5 (3:2:3 - N:50) 0,265 COMPO® HAKAPHOS rojo (18-18-18); *0,02 $\mathrm{H}_{3} \mathrm{PO}_{4}$ al $85 \%$.

T6 (3:2:3 - N:100) 0,55 COMPO® HAKAPHOS rojo (18-18-18); *0,02 $\mathrm{H}_{3} \mathrm{PO}_{4}$ al $85 \%$ y $0,043 \mathrm{KH}_{2} \mathrm{PO}_{4}$.

T7 (3:2:3 - N:150) 0,83 COMPO ${ }^{\circledR}$ HAKAPHOS rojo (18-18-18); *0,02 $\mathrm{H}_{3} \mathrm{PO}_{4}$ al $85 \%$; 0,057 $\mathrm{KH}_{2} \mathrm{PO}_{4}$ y $0,35 \mathrm{NH}_{4} \mathrm{H}_{2} \mathrm{PO}_{4}$.

T8 (3:2:3 - N:200) 1,06 COMPO® HAKAPHOS rojo (18-18-18); *0,02 $\mathrm{H}_{3} \mathrm{PO}_{4}$ al $85 \%$; 0,1 $\mathrm{KH}_{2} \mathrm{PO}_{4}$ y $0,061 \mathrm{NH}_{4} \mathrm{H}_{2} \mathrm{PO}_{4}$.

*: mililitros - milliliters (ml)

superficie del sustrato. Para la determinación de estos parámetros morfológicos se utilizó un diseño con submuestreo tomando cinco plantas por tratamiento por bloque elegidas al azar. Ambas variables se midieron con un calibre digital, con una precisión de $0,1 \mathrm{~mm}$.

La biomasa seca se determinó seleccionando cinco plantas por bloque, elegidas al azar (25 plantas por tratamiento). Estas se lavaron para eliminar restos de sustrato adherido y se secaron cuidadosamente. Posteriormente se seccionaron, separando la parte aérea de la radical, colocándolas en bolsas de papel rotuladas en forma independiente, y se llevaron a estufa a $80{ }^{\circ} \mathrm{C} \pm 2{ }^{\circ} \mathrm{C}$ hasta peso constante. Se determinaron los pesos de la porción aérea (PSA) y de la porción radical (PSR) utilizando una balanza digital con una precisión de $0,01 \mathrm{~g}$. La biomasa total (PST) se determinó mediante la suma de los pesos de la porción aérea y la radical.

Se midieron los contenidos de nitrógeno, fósforo, potasio, calcio y magnesio en la parte aérea del plantín. Los análisis fueron realizados en el Laboratorio de Análisis de Suelos del CRUB Universidad Nacional del Comahue, San Carlos de Bariloche. El nitrógeno total $\left(\mathrm{N}_{\mathrm{T}}\right)$ se determinó con un analizador de carbono-nitrógeno, combustión a $900{ }^{\circ} \mathrm{C}$, Serie Thermo Electron Corporation, NC Soil analyzer Flash EA 1112. El fósforo total $\left(\mathrm{P}_{\mathrm{T}}\right)$ se determinó por mineralización de la muestra por digestión seca y cuantificación por colorimetría: método del ácido ascórbico. Para el potasio, calcio y magnesio $\left(\mathrm{K}_{\mathrm{T}}, \mathrm{Ca}_{\mathrm{T}}\right.$ y $\left.\mathrm{Mg}_{\mathrm{T}}\right)$ se utilizó el método de mineralización de la muestra por digestión seca y cuantificación por absorción atómica. Las muestras consistieron de un mínimo requerido de $2,5 \mathrm{~g}$ de materia seca, obtenidos de treinta plantines por bloque de cada tratamiento.

El potencial de crecimiento radical (PCR) definido como la capacidad de una planta para iniciar y/o elongar sus raíces cuando estas se mantienen en un medio favo- rable, se determinó utilizando una cámara aeropónica de fabricación propia. La misma está compuesta de una batea de acero inoxidable de $60 \mathrm{~cm} \times 80 \mathrm{~cm} \times 75 \mathrm{~cm}$ de alto, con una tapa formada por tablas de madera con burletes de goma en sus cantos que actúan como sistema de sujeción de los plantines, permitiendo que las raíces queden suspendidas en el aire dentro de la batea, y la parte aérea se ubique hacia el exterior de la misma. La cámara posee un sistema de iluminación formado por tres tubos fluorescentes que generan sobre la porción aérea de las plantas una densidad de flujo de fotones (DFFF) de $40 \mu \mathrm{mol} \mathrm{m}^{-2} \mathrm{~s}^{-1} \mathrm{y}$ dentro de la batea un sistema de aspersión sobre las raíces por micro-difusores. Para el ensayo en la cámara aeropónica se eligieron al azar cinco plantas por bloque (veinticinco plantas por tratamiento), extrayéndolas del ensayo de invernáculo la primera quincena de agosto, con el crecimiento radical completamente detenido (caracterizado por la desaparición de puntas blancas en las raíces). Se lavaron las raíces para eliminar restos de sustrato y en caso de existir raíces no suberizadas fueron eliminadas. Los plantines se colocaron en la cámara aeropónica por 28 días, humectando los sistemas radicales constantemente con pulsos de agua atomizada de 10 segundos de duración con intervalos de 6 min. La temperatura del agua se mantuvo a $20^{\circ} \mathrm{C}$ bajo un fotoperiodo de 14/10 h de luz/oscuridad. Una vez terminado el ensayo en la cámara aeropónica se procedió a determinar el potencial de crecimiento radical utilizando la clasificación propuesta por Burdett (1979), la que se basa en una escala ordinal que toma en cuenta el número total de raíces nuevas y el número de raíces nuevas $>1 \mathrm{~cm}$ de largo, categorizando a las plantas en seis clases numeradas del 0 al 5 de la siguiente manera: Clase 0: no se identifican raíces nuevas; Clase 1: se identifican raíces nuevas pero ninguna $>1 \mathrm{~cm}$; Clase 2: 1 a 3 raíces nuevas $>1 \mathrm{~cm}$; Clase 3: 4 a 10 raíces nuevas $>1 \mathrm{~cm}$; Clase $4: 10$ a 30 raíces nuevas $>1 \mathrm{~cm}$; Clase 5: más de 30 raíces nuevas $>1 \mathrm{~cm}$. 
Diseño experimental y análisis estadístico. Se utilizó un diseño de bloques completos al azar (DBCA), disponiendo los ocho tratamientos en cinco bloques. Cada unidad muestral se conformó por cuatro bandejas de 30 plantines cada una, de modo que todo el ensayo estuvo compuesto por 160 bandejas, o sea 4.800 plantines. Las plantas de la periferia de la bandeja no se midieron con el fin de evitar el efecto borde.

Para comprobar el efecto de los tratamientos se realizaron análisis de la varianza (ANDEVA) para cada una de las variables consideradas, excepto PCR. En los casos en que se encontraron diferencias entre los tratamientos se utilizó la prueba de LSD Fisher $(\alpha=0,05)$ con corrección de Bonferroni. En el caso del PCR, por tratarse de una variable ordinal, se utilizó la prueba no paramétrica de Friedman. El procesamiento de los datos se realizó con el programa estadístico InfoStat/ Profesional, versión 2016.

\section{RESULTADOS}

Parámetros morfológicos. La altura media de los plantines al concluir el primer ciclo de crecimiento fue de 58,33 \pm 9,39 $\mathrm{mm}$. Los plantines sometidos al T5 fueron los más altos, mostrando diferencias significativas $(P=0,0009)$ con respecto a los del T3 y el T4 que presentaron los menores crecimientos (la diferencia entre los mismos fue cercana al $28 \%$ ). El diámetro medio de los plantines de todo el ensayo fue de $1,11 \pm 0,14 \mathrm{~mm}$; el diámetro del T5 fue un $24 \%$ mayor a los alcanzados por los tratamientos que presentaron los menores desarrollos (T2 y T3), diferenciándose significativamente $(P<0,0001)$ con el resto de los tratamientos, a excepción del T6. El comportamiento comparativo de los datos de la biomasa aérea (PSA) (media del ensayo: $0,23 \pm 0,09 \mathrm{~g}$ ) fue igual al reflejado por la variable diámetro, siendo T5 el tratamiento de mayor valor, dife- renciándose significativamente $(P<0,0001)$ de todos los tratamientos, salvo de T6 (cuadro 2).

En la biomasa radical (PSR) (media del ensayo: 0,14 $\pm 0,09 \mathrm{~g})$ los tratamientos T5 y T6 difirieron significativamente $(P<0,0001)$ con aquellos tratamientos en los cuales no se equiparó la concentración de nitrógeno con la de potasio (relación 3:2:1), siendo T5 el que presentó mayor desarrollo (68\% más que los tratamientos de menor desarrollo) (figura 1A). Si bien todos los tratamientos donde se equiparó la concentración de nitrógeno y potasio (relación 3:2:3) el desarrollo en biomasa total fue mayor, solo T5 y T6 mostraron diferencias significativas con los tratamientos con relaciones 3:2:1 (figura 1B).

$\mathrm{Al}$ analizar la relación entre la biomasa aérea y radical (PSA/PSR) se observó que los tratamientos T5 al T8 (relación $3: 2: 3)$ tuvieron una asignación de biomasa más equilibrada, obteniéndose un valor promedio de 1,41 ; mientras que en los tratamientos T1 al T4 con relaciones N:P:K de $3: 2: 1$, el valor de relación de biomasas fue en promedio 2,28 , evidenciando una mayor asignación de biomasa a la porción aérea en detrimento de la radical (figura 1C).

Estatus nutricional. El estado nutricional de las plantas mostró variaciones entre los tratamientos, para algunos de los elementos esenciales analizados. En el caso del nitrógeno los mayores valores de concentración en la porción aérea correspondieron al tratamiento $\mathrm{T} 8$, diferenciándose significativamente $(P<0,0001)$ del resto de los tratamientos, a excepción del T7. Los tratamientos T1 y T5 se diferenciaron de los tratamientos T4, T6, T7 y T8 (figura 2A). El fósforo no presentó diferencias significativas entre ningún tratamiento, mostrando un valor promedio de $0,28 \pm$ $0,08 \%$. En el caso del potasio el T1 fue el que mostró mayor concentración y se diferenció significativamente $(P<0,0001)$ del resto de los tratamientos, adicionalmente

Cuadro 2. Parámetros morfológicos de los plantines de Autrocedrus chilensis sometidos a los diferentes tratamientos.

Morphological parameters of the Austrocedrus chilensis seedlings submitted to different treatments.

\begin{tabular}{cccc}
\hline \multirow{2}{*}{ Tratamiento } & \multicolumn{3}{c}{ Valor promedio \pm desviación estándar $(\mathrm{n}=5)$} \\
\cline { 2 - 4 } & Altura $(\mathrm{mm})$ & Diámetro $(\mathrm{mm})$ & Biomasa seca aérea $(\mathrm{g})$ \\
\hline T1 & $63,0 \pm 4,68 \mathrm{ab}$ & $1,07 \pm 0,09 \mathrm{bc}$ & $0,21 \pm 0,04 \mathrm{bc}$ \\
T2 & $55,1 \pm 1,82 \mathrm{ab}$ & $0,99 \pm 0,04 \mathrm{c}$ & $0,19 \pm 0,05 \mathrm{bc}$ \\
T3 & $50,4 \pm 6,12 \mathrm{~b}$ & $0,98 \pm 0,08 \mathrm{c}$ & $0,17 \pm 0,06 \mathrm{c}$ \\
T4 & $50,1 \pm 3,52 \mathrm{~b}$ & $1,07 \pm 0,06 \mathrm{bc} 03 \mathrm{bc}$ \\
T5 & $69,4 \pm 12,01 \mathrm{a}$ & $1,30 \pm 0,14 \mathrm{a}$ & $0,36 \pm 0,09 \mathrm{a}$ \\
T6 & $65,1 \pm 11,54 \mathrm{ab}$ & $1,27 \pm 0,15 \mathrm{ab}$ & $0,33 \pm 0,11 \mathrm{ab}$ \\
T7 & $58,6 \pm 4,79 \mathrm{ab}$ & $1,10 \pm 0,03 \mathrm{bc}$ & $0,21 \pm 0,04 \mathrm{bc}$ \\
T8 & $54,4 \pm 6,65 \mathrm{ab}$ & $1,09 \pm 0,09 \mathrm{bc}$ & $0,19 \pm 0,06 \mathrm{bc}$ \\
\hline
\end{tabular}

Letras diferentes indican diferencias significativas / Different letters indicate significant differences (Fisher, $P<0,05$ ). 

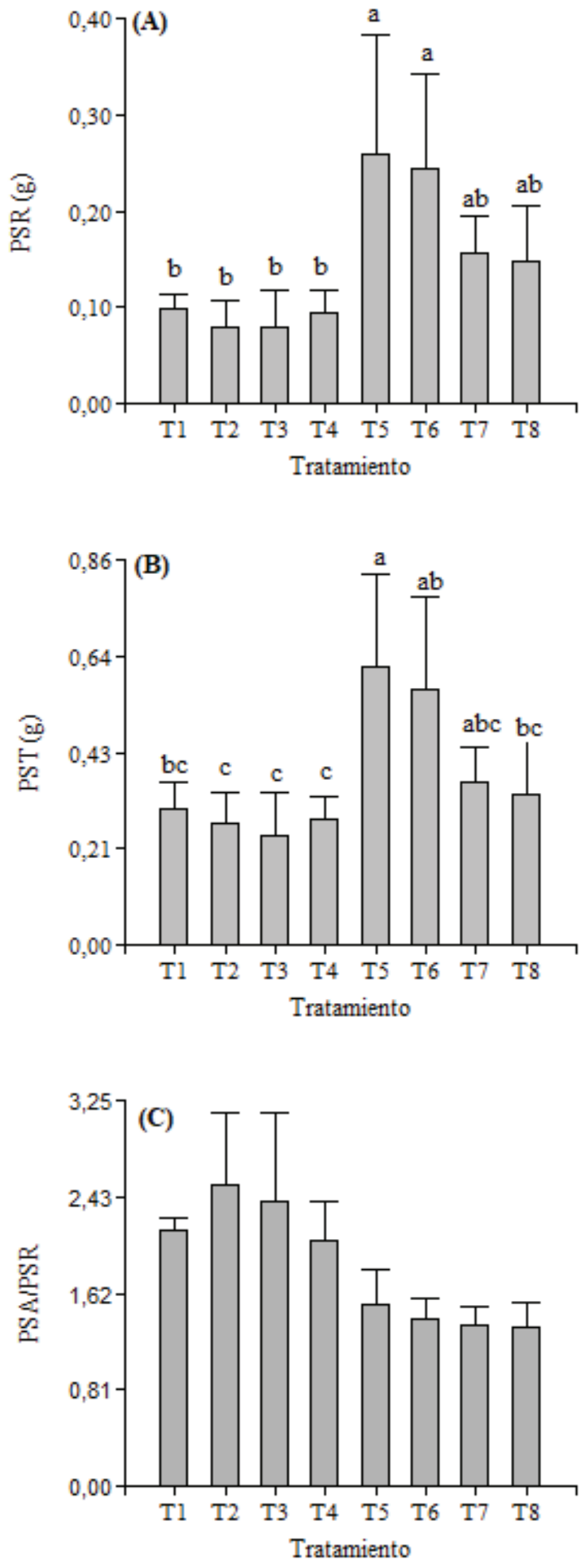

Figura 1. Parámetros morfológicos de los plantines de Austrocedrus chilensis sometidos a los distintos tratamientos T1-T8. (A) Biomasa radical seca (PSR). (B) Biomasa total seca (PST). (C) Relación biomasa aérea/biomasa radical (PSA/PSR). Los valores seguidos por la misma letra por tratamiento no presentan diferencias significativas (Fisher, $P<0,05$ ).

Morphological parameters of Austrocedrus chilensis seedlings subjected to treatments T1-T8. (A) Root dry biomass (PSR). (B) Total dry biomass (PST). Aboveground/underground dry biomass ratio (PSA/ PSR). Different letters indicate significant differences (Fisher, $P<0.05$ ). el T7 se diferenció también de T4 y de T6 (figura 2B). El calcio no mostró diferencias significativas entre los tratamientos (valor promedio de $0,39 \pm 0,08 \%$ ), en tanto que para el magnesio los tratamientos con relaciones 3:2:1 se diferenciaron significativamente $(P<0,0001)$ con los de relación 3:2:3, mostrando valores medios de $0,21 \pm 0,03 \%$ y $0,10 \pm 0,02 \%$, respectivamente.

Potencial de crecimiento radical (PCR). Ninguna planta ensayada alcanzó la clase 5 de potencial de crecimiento radical, y en general los valores observados resultaron bajos. Sin embargo, los tratamientos con relaciones 3:2:3
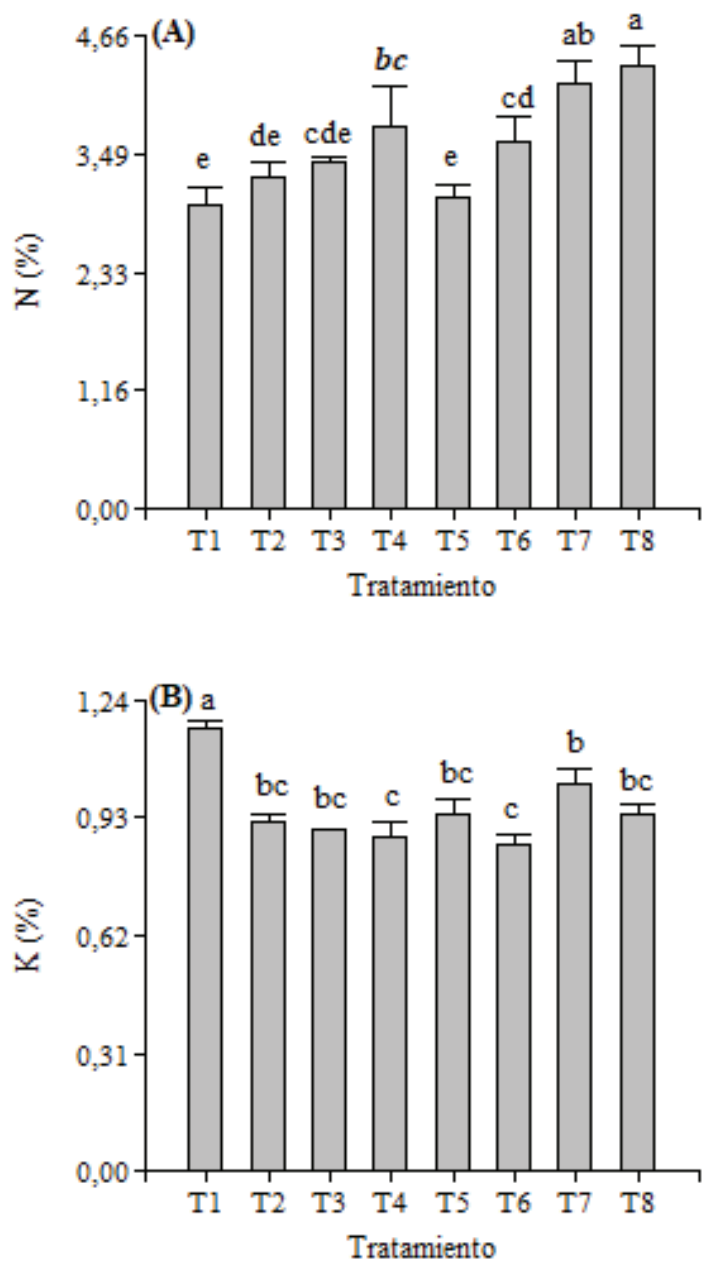

Figura 2. Concentración de nutrientes en la parte aérea de plantines de Austrocedrus chilensis sometidos a los distintos tratamientos T1-T8. (A) Concentración de nitrógeno (N) total en porcentaje de materia seca. (B) Concentración de potasio (K) en porcentaje de materia seca. Los valores seguidos por la misma letra por tratamiento no presentan diferencias significativas (Fisher, $P<0,05$ ).

Nutrients concentration in the aboveground tissues of Austrocedrus chilensis seedlings subjected to treatments T1-T8. (A) $\mathrm{N}$ concentration in percentage of dry biomass. (B) $\mathrm{K}$ concentration in percentage of dry biomass. Different letters indicate significant differences (Fisher, $P<0.05$ ). 
presentaron mejor comportamiento con respecto a esta variable que aquellos con relaciones $3: 2: 1$, mostrando en general mayor porcentaje de plantines ubicados entre las clases 2, 3 y 4 . En los tratamientos donde no se equiparó el nitrógeno con el potasio el mayor porcentaje de plantas se ubicó entre las clases 0 y 1 (cuadro 3 ).

El tratamiento $\mathrm{T} 6$, que produjo los plantines de las clases más altas de PCR, se diferenció significativamente de los tratamientos con relaciones 3:2:1 $(P=0,0016)$, mientras que el T2 y T4, que produjeron los plantines de clases más bajas de PCR, se diferenciaron de los tratamientos de relaciones 3:2:3 (cuadro 4).

Cuadro 3. Participación porcentual de clases de potencial de crecimiento radical (PCR) según la clasificación de Burdett en los tratamientos ensayados.

Percentage of each class of RGP according to the Burdett classification in the treatments assayed.

\begin{tabular}{ccccccccc}
\hline \multirow{2}{*}{ Clases de PCR } & \multicolumn{1}{c}{ Tratamientos } \\
\cline { 2 - 9 } & T1 & T2 & T3 & T4 & T5 & T6 & T7 & T8 \\
\hline 0 & 20 & 20 & 20 & 40 & 0 & 0 & 40 & 20 \\
1 & 20 & 60 & 40 & 20 & 0 & 0 & 20 & 20 \\
2 & 60 & 20 & 20 & 20 & 80 & 60 & 40 & 40 \\
3 & 0 & 0 & 20 & 0 & 20 & 20 & 0 & 20 \\
4 & 0 & 0 & 0 & 0 & 0 & 20 & 0 & 0 \\
5 & 0 & 0 & 0 & 0 & 0 & 0 & 0 & 0 \\
\hline
\end{tabular}

Cuadro 4. Potencial de crecimiento radical (PCR) de plantines de Austrocedrus chilensis sometidos a los distintos tratamientos T1-T8.

Radical Growth Potential (RGP) of Austrocedrus chilensis seedlings submitted to different T1-T8 treatments.

\begin{tabular}{ccc}
\hline \multirow{2}{*}{ Tratamientos } & \multicolumn{2}{c}{ Valores promedio de PCR } \\
\cline { 2 - 3 } & suma (Ranks) & media (Ranks) \\
\hline T4 & 12 & $2,4 \mathrm{a}$ \\
T2 & 12 & $2,4 \mathrm{ab}$ \\
T1 & 17,5 & $3,5 \mathrm{abc}$ \\
T3 & 19,5 & $3,9 \mathrm{abcd}$ \\
T7 & 26 & $5,2 \mathrm{cde}$ \\
T5 & 27 & $5,4 \mathrm{cde}$ \\
T8 & 29 & $5,8 \mathrm{cde}$ \\
T6 & 37 & $7,4 \mathrm{e}$ \\
\hline
\end{tabular}

Análisis de la varianza no paramétrico de Friedman. Distintas letras indican diferencias significativas / Friedman non-parametric analysis of variance. Different letters indicate significant differences $(P<0.05)$.

\section{DISCUSIÓN}

De los resultados obtenidos en los parámetros morfológicos se observa que los tratamientos que presentaron descompensaciones entre la biomasa aérea y biomasa radical, evidenciadas por índices de PSA/PSR más elevados, produjeron un menor desarrollo de la biomasa total. Si bien los tratamientos fueron aplicados durante la etapa de crecimiento rápido, en la que las condiciones de disponibilidad de agua y nutrientes no eran limitantes, las variables analizadas fueron determinadas al finalizar la etapa de rustificación, la que se caracteriza por someter al plantín, durante tres meses a condiciones ambientales y de manejo adversas, modificando los contenidos hídricos del medio de crecimiento, la disponibilidad de nutrientes y las temperaturas. En este escenario, el desbalance entre la parte transpirante y absorbente pudo haber afectado el desarrollo de la biomasa total. Si bien en este estudio no se midieron los potenciales hídricos en hoja al mediodía y tomando en cuenta que los plantines de A. chilensis se caracterizan por poseer un fuerte control estomático (Gyenge et al. 2007), es probable que la falta de compensación en la relación parte aérea/parte radical en los tratamientos con relaciones $3: 2: 1$, haya provocado una caída en el potencial hídrico foliar, generando una menor conductancia estomática con la subsecuente disminución en la captura de carbono, lo que pudo traducirse en un menor desarrollo de biomasa total. En esta línea, Scholz et al. (2014) mencionan que el control estomático observado en ciprés tiene el costo de reducir la captura de carbono, pero el beneficio de mantener potenciales hídricos relativamente elevados reduciendo la posibilidad de que la planta alcance umbrales de daños por sequía irreversibles. Por otro lado, en conjunto con un mejor balance de biomasas, los tratamientos con relaciones 3:2:3 mostraron mayor desarrollo radical que los tratamientos con relaciones $3: 2: 1$, pudiendo haber generado una mayor eficiencia con respecto a la captación de recursos (agua y nutrientes), traduciéndose en la mayor biomasa total lograda.

A pesar de que los datos del análisis foliar muestran que la concentración de nitrógeno en hojas aumenta en forma directamente proporcional con la concentración del elemento en la solución nutritiva, esta mayor concentración no se tradujo en un mayor crecimiento de las variables morfológicas evaluadas, mostrando, por el contrario, en los tratamientos de relación 3:2:3 un comportamiento inversamente proporcional al mismo. Algunos investigadores consideran que el "consumo de lujo" (aumento de la disponibilidad de un nutriente que no genera aumento en la tasa de crecimiento) no es perjudicial para la planta, sino meramente un desperdicio de fertilizante. Sin embargo, existen evidencias que muestran que elevados contenidos de nutrientes foliares (especialmente de nitrógeno) pueden ser dañinos (Landis et al. 1989). Este comportamiento de A. chilensis coincide con lo observado por Ingestad (1979) en experimentos con Pinus sylvestris Baumg. y Picea abies 
(L.) H. Karst con 20 a $1200 \mathrm{mg} \mathrm{L}^{-1}$ de nitrógeno. En ambas especies encontró que el crecimiento declinaba cuando las concentraciones foliares estaban entre 2,7 y $3,4 \%$, recomendando concentraciones de nitrógeno de 20 a $50 \mathrm{mg} \mathrm{L}^{-1}$ para $P$. sylvestris y de 60 a $100 \mathrm{mg} \mathrm{L}^{-1}$ para $P$. abies. Wang et al. (2015) mencionan en su trabajo realizado sobre fertilización exponencial con nitrógeno en Pinus tabuliformis Carr., que una disminución abrupta de la biomasa seca del plantín indicaría niveles tóxicos del elemento nutriente. En esta misma línea, Razaq et al. (2017) demostraron en Acer mono Maxim. que la administración de suplementos de nitrógeno puede aumentar los parámetros de crecimiento hasta cierto punto, teniendo efecto negativo a niveles más elevados. La disminución en biomasa mostrada por los plantines de $A$. chilensis entre los tratamientos de la relación $3: 2: 3$, podría estar indicando un efecto de toxicidad en relación a las concentraciones de nitrógeno. Por otro lado, Faustino et al. (2013) demostraron que en ensayos con fertilización de nitrógeno y fósforo, realizados sobre plantines puestos a campo de Pinus taeda Blanco, el crecimiento de las plantas fertilizadas con nitrógeno se vio afectado, atribuyendo dicho efecto a cambios en algunos rasgos de la arquitectura hidráulica que incidieron en un desbalance hídrico de las plantas afectando la tasa de crecimiento de las mismas. En este trabajo, los elevados valores de la relación de biomasas PSA/PSR, presentados por los tratamientos con relaciones $3: 2: 1$, expresan un fuerte desbalance entre la porción transpirante y absorbente, pudiendo ser este rasgo el responsable de la reducción de la tasa de crecimiento de los plantines.

Si bien el control de los niveles de nitrógeno es el factor más importante para manipular el crecimiento de las plantas (Landis et al. 1989), las observaciones del presente trabajo muestran que el manejo del potasio tiene gran influencia en el crecimiento de los plantines de A. chilensis, provocando un mayor desarrollo de las plantas que se cultivaron bajo las soluciones donde se equiparó el nitrógeno con el potasio.

Se observa que el aumento del potasio en las soluciones de los tratamientos de relación 3:2:3 aumenta la concentración de nitrógeno en la parte aérea, acompañando el mayor crecimiento de la misma. Posiblemente este aumento es provocado por la mayor asimilación de nitrógeno en forma de nitratos, debido a que los cationes potasio producen un efecto sinérgico en la absorción que realiza la planta de dicho anión. De forma contraria, la tasa de captación del magnesio se ve fuertemente deprimida por la acción antagónica de otros cationes como el potasio, amonio, calcio y manganeso (Garcés San Martin 2002). Esto se ve reflejado en el presente estudio, ya que los tratamientos donde se aumentó el potasio mostraron una menor concentración foliar del mismo, a pesar de que en estas soluciones la concentración de magnesio fue de dos a tres veces mayor que en las cuatro soluciones nutritivas de los tratamientos con relaciones $3: 2: 1$, presentando contenidos foliares promedios de $0,1 \%$ y $0,2 \%$, respectiva- mente. Como función principal del magnesio se identifican: su rol como átomo central de la molécula de clorofila y su participación en muchos procesos esenciales para el desarrollo normal de la planta, destacándose su función como elemento puente en la agregación de subunidades ribosómicas (proceso necesario para la síntesis proteica), modulador de la actividad de Rubisco en el estroma y promotor de reacciones enzimáticas. La deficiencia de magnesio puede provocar la limitación del suministro de carbohidratos a las raíces deteriorando fuertemente el crecimiento radical e incrementando la relación peso seco vástago-raíz (Marschner 2012). En este estudio, si bien se observa una diferencia significativa en los contenidos foliares entre los tratamientos de proporciones 3:2:1 y $3: 2: 3$, esta no tuvo incidencia en términos de crecimiento, presentando mayores desarrollos las plantas con menores concentraciones de magnesio, poniendo en evidencia que el mismo se encontró para todos los casos más allá del nivel limitante para el crecimiento y por debajo de los niveles tóxicos.

Existen escasos trabajos que incluyen el análisis foliar de nutrientes minerales entre las variables a evaluar en la viverización de $A$. chilensis. Por otro lado, para hacer diagnósticos es necesario disponer de estados nutricionales de comparación que relacionen, por ejemplo, nutrición con calidad y rendimiento. Uno de los pocos trabajos que realizan un análisis del estatus nutricional de plantines de A. chilensis cultivados en vivero es el realizado por Basil et al. (2009) arrojando concentraciones foliares promedio de $1,19 \%$ de nitrógeno; $0,46 \%$ de fósforo; $1,03 \%$ de potasio; $1 \%$ de calcio y $0,24 \%$ de magnesio en el tratamiento que produjo los mejores resultados. Estos valores difieren de los observados en el presente trabajo, sobre todo en el nitrógeno y el calcio. Estas diferencias podrían deberse al hecho de que en el trabajo de Basil et al. (2009) las plantas analizadas eran de tres años de edad y se produjeron bajo un régimen de cultivo en el que se utilizó compost como herramienta fertilizante, mientras que en el presente trabajo se analizaron plantas más jóvenes cultivadas bajo un método semi-controlado y bajo fertirriego, lo que posiblemente haya aumentado la disponibilidad de dichos elementos esenciales y mejorado las condiciones para su absorción.

Si bien los plantines de $A$. chilensis de los tratamientos con proporciones 3:2:3 mostraron valores de potencial de crecimiento radical superiores a los de proporciones $3: 2: 1$, en su conjunto presentaron un bajo desempeño con respecto a esta variable. Venegas Ibañez (2000) en un trabajo realizado en Eucalyptus globulus Labill y Eucalyptus nitens Maiden, donde evaluaron potencial de crecimiento radical en relación a distintos esquemas de fertilización, obtuvieron resultados opuestos entre estas dos especies. Mientras que E. globulus respondió mejor a altas concentraciones foliares de nitrógeno y bajas de potasio, E. nitens obtuvo mejores valores de potencial de crecimiento radical en las menores concentraciones de nitrógeno y mayores de po- 
tasio, mostrando esta última especie un comportamiento similar al expresado por A. chilensis en el presente trabajo. Por otro lado, Donald (1988) encontró en ensayos realizados con plantines de Pinus radiata D. Don que el aumento de nitrógeno fomentaba la formación de nuevas raíces, mientras que el aumento del potasio lo disminuía. Los estudios mencionados ponen en evidencia que las respuestas del potencial de crecimiento radical en relación a esquemas de fertilización parecen depender de la especie con la que se trabaje. Por último, Ritchie y Tanaka (1990) señalan que el potencial de crecimiento radical parece estar regulado por factores fisiológicos internos como la intensidad de la dormancia aérea y la presión sobre las reservas de carbono en el desarrollo aéreo, señalando como puntos de máximo valor del mismo cuando la dormancia es débil y la parte aérea no se está expandiendo. En este trabajo el potencial de crecimiento radical fue medido en el mes de agosto, y consecuentemente es posible que los plantines de $A$. chilensis se encontraran en un estado de dormancia avanzada, lo que explicaría los bajos valores generales del mismo. Sería necesario realizar el análisis de esta variable en las distintas etapas fenológicas del cultivo para poder determinar su secuencia cíclica y de esta manera fijar las etapas del cultivo más propicias para su medición transformándolo en un indicador de calidad confiable para la especie estudiada.

\section{CONCLUSIONES}

Las evidencias presentadas en este trabajo demuestran que el crecimiento de los plantines de $A$. chilensis durante la viverización es influenciado por la relación nitrógeno:potasio del esquema de fertilización, durante la etapa de pleno crecimiento. Para la misma proporción de nitrógeno y potasio, concentraciones mayores de nitrógeno producen una inhibición del crecimiento. Las relaciones donde se equiparó el nitrógeno con el potasio mostraron una asignación de biomasa más equilibrada entre las porciones aérea y radical de la planta, y un mayor crecimiento con respecto a las relaciones donde no se equipararon estos elementos. Por otro lado, iguales proporciones de nitrógeno:potasio y bajas concentraciones de nitrógeno mejoraron el comportamiento del potencial de crecimiento radical. Este estudio pone en evidencia que concentraciones de nitrógeno del orden de los 50 a $100 \mathrm{mg} \mathrm{L}^{-1}$ en proporciones equilibradas con el potasio, aplicados durante la etapa de pleno crecimiento, generan no solo un mayor crecimiento de los plantines en vivero, sino que también mejoran atributos morfológicos e indicadores de calidad usados para predecir el desempeño a campo. Además, estos conocimientos sobre el manejo del cultivo permiten reducir el tiempo de cultivo en vivero de las plantas de A. chilensis. En futuros estudios se incluirá el análisis de parámetros de la arquitectura hidráulica para analizar con mayor detalle la dinámica de crecimiento y su relación con el contenido foliar de nutrientes.

\section{REFERENCIAS}

Azpilicueta MM, S Varela, A Martínez, L Gallo. 2010. Manual de viverización, cultivo y plantación de Roble Pellín en el norte de la región Andino Patagónica. Buenos Aires, Argentina. Ediciones INTA. 74 p.

Basil G, M Leanza, MJ Mazzarino, L Roselli, L Lugano, L Tejera. 2002. Nutrición de plantines de coníferas en viveros del NO de la Patagonia argentina. Informaciones Agronómicas del Cono Sur 15: 12-15.

Basil G, MJ Mazzarino, L Roselli, F Letourneau. 2009. Efecto del compost de biosólidos en la producción de plantines de Austrocedrus chilensis (ciprés de la cordillera). Ciencia del Suelo 27 (1): 49-55.

Burdett A. 1979. New methods for measuring root growth capacity: their value in assessing lodge pole pine stock quality. Canadian Journal of Forest Research 9(1): 63-67. DOI: 10.1139/x79-011

Donald D. 1988. The application of inorganic fertilizers to conditioned Pinus radiata to lifting as a means of improving root growth capacity. South African Forestry Journal 146: 23-25. DOI: 10.1080/00382167.1988.9630354

Donoso C. 1993. Bosques Templados de Chile y Argentina: variación, estructura y dinámica. Santiago, Chile. Editorial Universitaria. 484 p.

Enricci JA, DS Massone. 2003. Producción de plantines plug +0 de Austrocedrus chilensis en Patagonia Argentina. XII Congreso Mundial Forestal. Québec, Canadá. Disponible en Http:// www.fao.org/DOCREP/ARTICLE//WFC/XII/0241-B3.HTM

Escobar R. 2007. Manual de viverización, Eucalyptus globulus a raíz cubierta. Proyecto "Desarrollo de estándares de origen de la semilla y calidad de la planta para el aumento de la productividad en plantaciones y bosques naturales". INNOVA-CHILE - CORFO. 230 p.

Fernández ME, JE Gyenge. 2010. Técnicas en medición de ecofisiología vegetal: conceptos y procedimientos. Buenos Aires, Argentina. Ediciones INTA. 140 p.

Faustino LI, NML Bulfe, MA Pinazo, SE Monteoliva, C Graciano. 2013. Dry weight partitioning and hydraulic traits in young Pinus taeda trees fertilized with nitrogen and phosphorus in a subtropical area. Tree Physiology 33(3): 241251. DOI: $10.1093 /$ treephys/tps 129

Garcés San Martín MA. 2002. Aportes de N, P, K y su combinación al incremento en biomasa en plantas de Eucalyptus globulus Labill. ssp. globulus. Tesis Ingeniero Forestal. Concepción, Chile. Facultad de Ciencias Forestales, Universidad de Concepción. $41 \mathrm{p}$.

Gyenge JE, ME Fernández, T Schlichter. 2007. Influence of radiation and drought on gas exchange of Austrocedrus chilensis seedlings. Bosque 28(3): 220-225. DOI: 10.4067/ S0717-92002007000300006.

Ingestad T. 1979. Mineral nutrient requirement of Pinus silvestris and Picea abies seedlings. Physiologia Plantarum 45(4):373-380. DOI: 10.1111/j.1399-3054.1979.tb02599.x

Landis T, RW Tinus, SE McDonald, JP Barnett. 1989. Seedling Nutrition and Irrigation, Volume 4. The Container Tree Nursery Manual. Washington DC, EE.UU. Department of Agriculture, Forest Service. 119 p.

Lavado R, MJ Mazzarino. 2005. Fertilización de Forestales. In Echeverría HE, FO García eds. Fertilidad de Suelos y Fertilización de Cultivos. Buenos Aires, Argentina. INTA. p. 
445-454.

Marschner H. 2012. Mineral nutrition of higher plants. Third Edition. London, UK. Academic Press. 651 p.

Mohr Bell D. 2015. Superficies afectadas por incendios en la región Bosque Andino Patagónico durante los veranos de 2013-2014 y 2014-2015. SAyDS - CIEFAP. 12 p. Disponible en: http://www.ciefap.org.ar/index.php/component/phocadownload/category/10-restauracion?download=79:supe rficie-afectada-por-incendios-en-la-region-bosque-andinopatagonico-durante-los-veranos-2013-2014-y-2014-2015

Pastorino MJ, LA Gallo, HH Hattemer. 2004. Genetic variation in natural populations of Austrocedrus chilensis, a cypress of the Andean-Patagonian Forest. Biochemical Systematics and Ecology 32(11): 993-1008.

Pastorino MJ, MM Fariña, D Bran, LA Gallo. 2006. Extremos geográficos de la distribución natural de Austrocedrus chilensis (Cupressaceae). Boletín de la Sociedad Argentina de Botánica 41(3-4): 307-311.

Pastorino MJ, AG Aparicio, MM Azpilicueta. 2015. Regiones de procedencia del Ciprés de la cordillera y bases conceptuales para el manejo de sus recursos genéticos en Argentina. Bariloche, Argentina. Ediciones INTA. 115 p.

Razaq M, P Zhang, HI Shen, Salahuddin. 2017. Influence of nitrogen and phosphorous on the growth and root morphology of Acer mono. PLOS ONE 12(2): e0171321.

Ritchie A, Y Tanaka. 1990. Root growth potential and the target seedling. In: Target Seedling Symposium: Proc., Combined Meeting Western Forest Nursery Associations. Rose R, S Campbell, T Landis eds. Oregon, EE.UU. United States Department of Agriculture, Forest Service. 37-52.

Schinelli Casares T. 2013. Producción de Nothofagus bajo condiciones controladas. Bariloche, Argentina. Ediciones INTA. 56 p.
Scholz FG, SJ Bucci, G Goldstein. 2014. Strong hydraulic segmentation and leaf senescence due to dehydration may trigger die-back in Nothofagus dombeyi under severe droughts: a comparison with the co-occurring Austrocedrus chilensis. Trees 28:1475-1487.

Urretavizcaya MF. 2001. Restauración de bosques quemados de Ciprés de la Cordillera en las provincias de Rio Negro y Chubut. Informe final Proyecto PAN (INTA-GTZ) 2001. Chubut, Argentina. CIEFAP. 11p.

Venegas Ibañez GA. 2000. Efecto de la fertilización de pre cosecha sobre el potencial de crecimiento radicular de plantas de Eucalyptus globulus y Eucalyptus nitens. Tesis Ingeniero Forestal. Santiago, Chile. Universidad de Chile. Facultad de Ciencias Básicas y Farmacéuticas. 61 p.

Wang J, Li G, JR Pinto, J Liu, W Shi, Y Liu. 2015. Both nursery and field performance determine suitable nitrogen supply of nursery-grown, exponentially fertilized Chinese pine. Silva Fennica 49(3): 1-13.

Watanabe M, Y Watanabe, S Kitaoka, H Utsugi, K Kita, T Koike. 2011. Growth and photosynthetic traits of hybrid larch F1 (Larix gmelinii var. japonica $\times$ L. kaempferi) under elevated $\mathrm{CO} 2$ concentration with low nutrient availability. Tree Physiology 31(9): 965-975. DOI: 10.1093/treephys/tpr059

Werdan K, HW Heldt, M Milovancev. 1975. The role of $\mathrm{pH}$ in the regulation of carbon fixation in the chloroplast stroma. Studies on $\mathrm{CO} 2$ fixation in the light and dark. Biochimica et Biophysica Acta 396(2): 276-292. DOI: 10.1016/00052728(75)90041-9

Wu W, GA Berkowitz. 1992. Stromal $\mathrm{pH}$ and photosynthesis are affected by electroneutral $\mathrm{K}+$ and $\mathrm{H}+$ exchange through chloroplast envelope ion channels. Plant Physiology 98(2): 666-672. DOI: 10.1104/pp.98.2.666 